\title{
The Critical Relationship between Climate Change Awareness and Action: An Origin-Based Perspective
}

Authors: ${ }^{1}$ Tina Roenhovde Tiller and ${ }^{2}$ Christian Schott

Affiliation: ${ }^{1}$ MODUL University Vienna, Austria; ${ }^{2}$ Victoria University of Wellington, New Zealand

https://doi.org/10.1080/10941665.2012.697648

\begin{abstract}
:
While it is now widely accepted by scientists and governments that human activity contributes to climate change, there is a lack of understanding whether this realisation is now gaining greater attraction with the general public than it had 5 or 10 years ago. Additional gaps in knowledge relate to the link between awareness and action, which could be hypothesised to have become stronger in light of evidence being produced of some projected climate changes occurring already. This article examines climate change awareness and the link with travelrelated decision-making by adopting an under-utilised origin perspective in Wellington, New Zealand. The findings, generated by a household mail survey, indicate that the majority of the respondents are aware of tourism's contribution to climate change and think that it is likely that their lives in New Zealand will be negatively affected by climate change. However, when examining the respondents' recent holiday decision-making, it is evident that for the overwhelming majority, climate change awareness does not appear to influence travel-related decisions. This article concludes by discussing demand-focused measures aimed at reducing the GHG emissions generated by tourism.
\end{abstract}

Key words: Leisure travel, climate change mitigation, awareness, travel behaviour, New Zealand

\section{Introduction}

Climate change, due to its manifold direct and indirect implications, is one of the defining challenges of the twenty-first century, and it is now accepted that human activity contributes to climate change (IPCC, 2007). As one form of human activity, tourism contributes in several ways: by contributing to emissions of GHGs through energy use; by encouraging land-use change; and most importantly by contributing to GHG emissions through the burning of fossil fuels in transportation of tourists (Gössling, 2002). According to UNWTO-UNEP-WMO (2008), the current proportion of GHG emissions attributed to tourism is estimated to be about $5 \%$ of 
total global emissions. While already a substantial contribution, this proportion is expected to increase in line with rapidly expanding numbers of international and domestic tourists forecast for the coming years; international tourist arrivals, for example, are forecast to reach 1.6 billion by 2020 compared with 922 million in 2008 (UNWTO, 2009). However, such a rise in international travel, particularly long haul, will jeopardise the future of the planet due to the associated GHG emissions (IPCC, 2007). The figures then highlight that changes will be necessary to lower tourism's GHG emissions. The options include demand-related changes such as travel to geographically and logistically closer destinations, use of low-emission or zeroemission modes of transport (where available), less energy-intensive stays at the destination, and ultimately less tourist travel per se.

Research exploring demand-side responses to the challenges presented by climate change has predominantly adopted a destination focus. However, in order to develop a comprehensive understanding of how people respond to the challenge, an origin perspective is important to capture a wide range of attitudes and behaviours. Barr, Shaw, Coles, and Prillwitz (2010) have conducted a study in the UK examining peoples' environmental attitudes at home compared with those on holiday. This study contributes some useful insights into the topic from a UK perspective; however, no evidence of origin-focused climate change demand research conducted in the Asia Pacific region could be found. In response, this article presents findings from a questionnaire study of Wellington residents (New Zealand) examining three research aims:

(1) explore the respondents' awareness of climate change and concern about its effects on their lives;

(2) examine the respondents' recent holiday decision-making to identify whether and how this awareness and/or concern impacts on their tourism-related decisions and behaviour; and

(3) identify preferences for demand-focused strategies aimed at reducing the GHG emissions generated by tourism.

\section{Literature}

While earlier studies conducted among tourists at holiday destinations have found a lack of awareness of tourism's contribution to climate change (Becken, 2007; Gössling, Bredberg, Randow, \& Sandström, 2006), recent research in Europe has concluded that climate change awareness among residents of industrialised societies is relatively high (Barr et al., 2010; Gössling, Haglund, Kallgren, Revahl, \& Hultman, 2009; Hares, Dickinson, \& Wilkes, 2010; 
Norgaard, 2006; World Bank, 2010). As awareness of climate change and its implications rises, concern about its effects, and indeed resultant action, is expected to become more common place. However, concerns about health, finances, and other social issues that appear more tangible to people have been found to be prioritised relative to climate change concern (NZBCSD, 2009). A number of studies have concluded that climate change action is not prioritised because many people regard it as an issue that is comparatively far removed in time and space (Lorenzoni, Nicholson-Cole, \& Whitmarsch, 2007; Lorenzoni \& Pidgeon, 2006; NZBCSD, 2009).

A study conducted a decade ago in Germany noted that the concern for the environment did not affect the choice of a holiday destination (Lübbert, 2001). This trend was echoed in a New Zealand context by Reiser and Simmons (2005) and Schott (2006), who concluded that although large groups of visitors reported awareness of environmental degradation and environmental concern, this rarely translated into environmentally friendly decision-making and holiday behaviour. Other studies have found that people are unwilling to forego the benefits of travel for the sake of the environment (Becken, 2007; Hares et al., 2010). This inconsistency between awareness and action is commonly referred to as the attitude-behaviour gap and has been mentioned in several studies that have examined tourism behaviour and climate change (Barr et al., 2010; Becken, 2007; Hares et al., 2010).

There has been much speculation about the reasons underlying the relatively small change in travel decision-making and behaviour in the face of increasing public awareness-building initiatives and media coverage of global environmental change. For example, Stoll-Kleemann, O'Riordan, and Jaeger (2001) suggested that a number of psychological mechanisms, including displacement of responsibility and denial, contribute to a lack of climate change mitigation. The researchers stated that "the most powerful zone for denial is the perceived unwillingness to abandon what appear as personal comfort and lifestyle-selected consumption and behaviour in the name of climate change mitigation" (Stoll-Kleemann et al., 2001, p. 113). This has been supported, among others, by Norgaard (2006), who researched "cultural denial" among Norwegian citizens. Her research concluded that people "do not want to know" and therefore either avoid information or create justifications for their lack of response to the threat of climate change. Seeking to increase psychology's contribution to understanding tourism demand research, Schott, Reisinger, and Milfont (2010) borrowed from the work of Pawlik (1991) and Milfont (2010) to build a psychology-informed insight into the climate changerelated barriers to action. The authors proposed five barriers: psychophysiological, temporal, judgemental, geographical, and social. Thus, some progress has been made with regard to understanding human failure to tackle climate change. Notwithstanding the value of these insights, it is important to also reassess peoples' behaviour in this context to determine 
whether the ever-greater amount of knowledge about climate change and the growing evidence of projected climate changes occurring already (Chug, 2011) have triggered notable behavioural change.

Further highlighting the critical need for changes to demand patterns, the current and foreseeable technological advances in transportation technology are considered to be insufficient in achieving noticeable reductions in tourism's GHG emissions without a concurrent change in tourist behaviour (Burns \& Bibbings, 2009; Peeters, 2010). Equally, current mitigation mechanisms and initiatives by the public and private sectors appear to be unable to control the further growth of tourism emissions as international tourist arrivals and GHG emissions continue to increase. Voluntary mitigation measures appear particularly ineffective (Becken, 2007; Lorenzoni et al., 2007) as they are often ignored or adopted for reasons other than concern for the environment (Whitmarsh, 2009). In a UK context, Hares et al. (2010) found that because climate change is considered too complex to be dealt with at a personal level, people want national governments to force behavioural change through legislation.

Thus far, research with a comparable focus has been either conducted in a European context, if an origin perspective was adopted, or conducted with tourists at a destination, thus limiting the representativeness of the population. Additionally, there is arguably a wider understanding of tourism's contribution to climate change now than during previous studies in the Asia Pacific region. Equally, more information about the nature and scale of both direct and indirect implications of climate change is now available from public-sector agencies, NGOs, and privatesector entities. Thus, in order to develop tools for mitigating the negative effects of tourism originating in the Pacific on the global environment, more information is needed about people's awareness of climate change, their concern about the challenges presented by climate change, and, importantly, whether this affects tourism-related decision-making.

\section{Methodology}

In order to develop a comprehensive picture of Wellington residents' climate change awareness and action, a self-administered household survey was designed based on the key themes that emerged from the related literature. The survey consisted of three broad sections pertaining to awareness and opinions about tourism and climate change, recent holiday decision-making and travel behaviour, and finally socio-demographic information. Both open-ended and closed questions were included to allow for the quantitative data (attitude scales and multiple responses) to be supported by unguided qualitative information. The survey was piloted with a sample of 200 households to assess the effectiveness of both the questionnaire and the methodology before the formal survey was commenced. 
The survey sample was drawn from Wellington City residents using a cluster sampling technique based on the City Council's register of suburbs to select eight suburbs using a structured approach. The aim was to reflect the city's population as closely as possible in terms of age, income, and education as these were highlighted as significant in previous studies. The data were collected during a 6week period in 2009 by delivering the questionnaire to the mailboxes of 1,590 dwellings in Wellington City. A total of 319 questionnaires were returned, which equates to a response rate of $19.9 \%$.

Limitations of this method include the inherent drawbacks of conducting self-administered household surveys, which include lack of control over who completes the questionnaire and lack of ability to clarify respondents' queries, as well as the fact that the topic is one that has been subject to much debate. As such, it cannot be ruled out that the questionnaire may have been completed in comparatively larger numbers by people who feel strongly about the topic. The level of education within the sample does not match the Wellington population as indicated in the 2006 census conducted by Statistics New Zealand, as there is an overrepresentation of people with higher education in the sample. Also, the population in the sample was generally more affluent than the census population and dominated by younger age segments (Table 1); however, the overall age and income discrepancies between the two data sets were relatively modest. 


\begin{tabular}{|l|c|c|}
\hline \multicolumn{3}{|c|}{ Table 1: Key Population Characteristics for Census 2006 and Sample Population } \\
\hline \multicolumn{3}{|c|}{ Age Group } \\
\hline $20-29$ (18-29 in sample) & $26 \%$ & Sample \\
\hline $30-39$ & $24 \%$ & $17 \%$ \\
\hline $40-49$ & $20 \%$ & $20 \%$ \\
\hline $50-59$ & $14 \%$ & $21 \%$ \\
\hline $60-69$ & $8 \%$ & $9 \%$ \\
\hline$>70$ & $8 \%$ & $6 \%$ \\
\hline \multicolumn{3}{|c|}{ Household Income (in NZ\$) } \\
\hline below 20 000 & $10 \%$ & $4 \%$ \\
\hline $20001-50$ 000 & $19 \%$ & $12 \%$ \\
\hline 50 001-100 000 & $27 \%$ & $30 \%$ \\
\hline 100 001 or above & $31 \%$ & $40 \%$ \\
\hline Not stated & $13 \%$ & $14 \%$ \\
\hline \multicolumn{3}{|c|}{} \\
\hline \multicolumn{3}{|c|}{ Education (Highest Qualification) } \\
\hline No Formal Qualification & $11 \%$ & $0 \%$ \\
\hline School Qualification & $33 \%$ & $20 \%$ \\
\hline Post School Qualification & $56 \%$ & $80 \%$ \\
\hline \multicolumn{2}{|c|}{} \\
\hline
\end{tabular}

Source: Statistics New Zealand (2011). Note: The census data are not always directly comparable to the sample data; for example, the census data include all age groups (including children), while the sample data only include respondents aged 18 and above. As a result, some of the census data were adjusted to allow for more informative comparison.

\section{Findings}

The findings are structured by initially presenting the respondents' awareness and concern about climate change, followed by tourism related decision-making and behaviour, before the article discusses the demand-side mitigation options. Where appropriate, a one-way ANOVA was utilised to test for variance between different respondent groups, complemented by Scheffe's post hoc comparisons to identify the significant relationships. Three variables (age, income, and level of education) were used to guide the comparative element of the analysis. Age was included as several studies on environmental opinions and behaviour discovered differences across different age groups (Hares et al., 2010; Jagers, 2009; Whitmarsh, 2009); 
Table 1 reports information about the age classifications used. Level of education is commonly assumed to be important in the formation of environmentally and socially concerned attitudes and behaviours (Jagers, 2009). For this analysis, education data that were more detailed than those given in Table 1 were utilised in order to detect nuances between different segments of the sample. Five educational categories were examined: "primary school", "secondary school", "high school certificate", "university undergraduate degree", and "postgraduate degree". Discretionary income is recognised as an important influence on the style of travel and time that can be spent away from home (Graburn, 1983). Thus, annual household income was also used to explore differences in the sample population; see Table 1 for income categories

\section{Attitudes to Climate Change and Tourism}

It has been argued by some that awareness of the impact of tourism on the global natural environment remains low despite much attention being paid to tourism's contribution to global warming by burning fossil fuels through travel to and from the destination (Gössling et al., 2006). To investigate whether this has changed over the last 5 years and whether this observation applies to New Zealand, the respondents were asked to indicate their agreement with the following statement on a scale of $1-5$, where $1=$ strongly agree and $5=$ strongly disagree: "Tourism within New Zealand does not contribute to global climate change". The statement was phrased in such a manner that the respondents had to consider the impact that tourism on a local scale had on the global climate. As such, disagreement with the statement would leave little doubt that the respondents believe that their tourism behaviours, even on a local scale, will have an effect on the global environment. The results indicate that the majority of the respondents are aware that tourism and climate change are linked, as $55.7 \%$ of the respondents either disagreed or disagreed strongly with the statement (Mean $=3.49$; Standard Deviation $=0.995$ ).

In order to identify differences between the respondent groups, a one-way ANOVA was used to test for variance across the aforementioned respondent characteristics: age, education, and household income. The variables that returned a significant difference were education $(F(4$, $290)=3.847, p=0.005)$ and age $(F(5,290)=3.568, p=0.004)$. Scheffe's post hoc comparison of the five education categories indicated that the people whose highest level of education was secondary school ( $\mathrm{M}=2.91,95 \% \mathrm{Cl}[2.52,3.29]$ ) exhibited significantly less disagreement that tourism in New Zealand has an impact on the global natural environment than the respondents who had a university undergraduate degree $(\mathrm{M}=3.65,95 \% \mathrm{Cl}[3.50,3.79])$ or a postgraduate degree $(\mathrm{M}=3.66,95 \% \mathrm{Cl}[3.35,3.96])$. These findings illustrate that the higher the level of education among the respondents, the stronger the statement of disagreement, indicating that awareness of the contribution of tourism to climate change increases with the level of formal education. 
Similarly, Scheffe's post hoc comparisons of the six age groups indicate that the respondents aged 70 years or above $(\mathrm{M}=2.78,95 \% \mathrm{Cl}[2.25,3.31])$ reported significantly higher agreement with the statement than the three youngest age groups in the sample: people aged 18-29 years $(\mathrm{M}=3.59,95 \% \mathrm{Cl}[3.31,3.87]), 30-39$ years $(\mathrm{M}=3.80,95 \% \mathrm{Cl}[3.55,4.04])$ and $40-49$ years ( $\mathrm{M}$ $=3.44,95 \% \mathrm{Cl}[3.33,3.75])$. This indicates that younger people in the sample are more aware of the relationship between travelling and its negative impact on the climate system than the oldest age group.

\section{Climate Change Impacts}

Researchers have noted that people are less likely to act in an environmentally friendly manner if they do not see the urgency of dealing with the threat that global climate change poses (Lorenzoni et al., 2007); people are often more concerned with problems that are seen as more pressing, such as personal health and security (Lorenzoni \& Pidgeon, 2006). Motivated by this proposition, this research sought to explore whether the respondents felt that climate change would have a negative effect on their daily lives within the next 20 years. A five-point Likert scale was used to assess the respondents' sense of urgency in dealing with the problems that climate change poses. Over two-thirds of the sample (67.2\%) reported that they believed that climate change would likely or very likely have negative effects within the next 20 years and thus acknowledged that negative implications of climate change may be felt in the very near future. A one-way ANOVA was again run to test for variance across age, education, and household income; however, no statistically significant results were returned for this question.

To gain further insight into the awareness of climate change impacts and to ascertain whether climate change continues to be regarded as a distant and currently intangible issue, the respondents were asked whether they have observed any evidence of climate change in their home environment during their life time. A total of $44.2 \%$ of the respondents reported that they had observed evidence of climate change in their home environment, which highlights that climate change is seen as a phenomenon that is both tangible and present in the minds of many respondents. Those who reported that they had observed climate change during their life time $(N=133$ ) were asked to describe the observations that they had made (Figure 1$)$. The most commonly reported observations were changes in weather patterns and/or temperature. Some respondents, for example, noted that summers have become hotter, while other comments related to the increase in rain and/or wind in Wellington. The respondents also commented on changing seasons, lack of snow cover, and melting glaciers. When relating these comments to the scientific records collected by New Zealand's National Institute of Water and Atmospheric Research (NIWA), many of the respondent observations find support. NIWA (2009) 
data show that numerous changes have occurred in New Zealand over the last 100 years including a rise in average temperature of 0.98 , a $16 \mathrm{~cm}$ rise in sea level averaged over the four main ports (Auckland, Wellington, Lyttelton, and Dunedin), and changes in frost and snow cover including glacial retreat.

\section{Figure 1: Changes to the environment observed by the respondents}

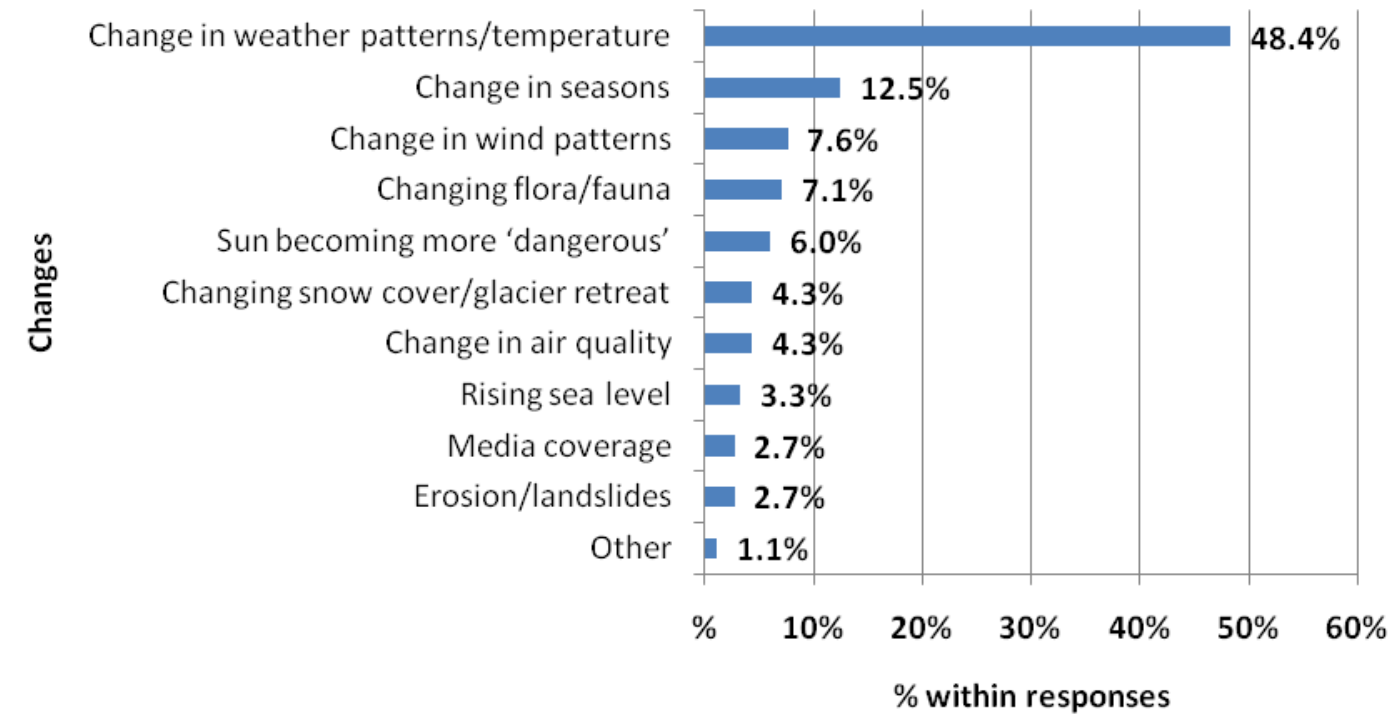

In summary, more than two-thirds of the respondents reported that they believed that climate change would likely or very likely have a negative effect on their daily lives in New Zealand within the next 20 years, while almost half of them reported that they have already observed evidence of climate change during their life time. The awareness of climate change, its impacts, and the increasingly tangible nature of this challenge is thus relatively high among the survey respondents. Recent studies conducted in Europe are consistent with this finding in the context of industrialised societies (Barr et al., 2010; Gössling et al., 2009; Hares et al., 2010; Norgaard, 2006; World Bank, 2010). This New Zealand-based study expands on this finding by documenting that nearly half of the respondents believe that they have observed evidence of climate change.

\section{Holiday decision making and behaviour}

Next, the analysis explored the influence of awareness of climate change and its impacts on the respondents' holiday decision-making and behaviour. This was motivated by the suggestion that environmental awareness and concern do not necessarily translate into environmentally responsible behaviour (Dolcinar \& Leisch, 2008; Fairweather, Maslin, \& Simmons, 2005; Lopez $\&$ Cuervo-Arango, 2008; Stoll-Kleemann et al., 2001) and the desire to validate whether this 
observation holds true despite the ever-increasing amount of press coverage, public debate, and freely available educational material.

Initially, the impact on leisure travel per se was investigated to determine whether concern about climate change leads some respondents to decide not to travel at all. Of the 319 respondents, only 7 reported that they do not travel for leisure purposes, as defined as all travel that is not related to business. In response to the question why they do not travel for leisure, the most common answer was financial constraints, followed by family constraints, lack of interest, and temporal constraints. Despite the fact that this question was designed as open ended and most respondents provided more than one reason, it is significant to note that none of the respondents mentioned climate change or the natural environment as a reason for not travelling for leisure purposes.

In order to assess the relationship between awareness of climate change and its implications and holiday decision-making and behaviour, the questionnaire asked those who reported having observed evidence of climate change whether these observations had influenced their travel decision-making or behaviour. Bearing in mind that 133 respondents had reported observing evidence of climate change, it needs to be highlighted that a relatively small number of people (30) responded to this question. This in itself is an important finding in that it suggests that the remaining 103 respondents have not altered their holiday decision-making or behaviour, which lends support to previous findings about environmental behaviour (Dolcinar \& Leisch, 2008; Fairweather et al., 2005; Lopez \& Cuervo-Arango, 2008; Schott, 2006; StollKleemann et al., 2001).

The answers provided by the 30 respondents were grouped according to their statements and a total of four groups emerged, which will be presented in turn. Interestingly, Group 1 (seven respondents) reported changes that are likely to increase rather than decrease an individual's contribution to climate change. The results show that the respondents who fall into this group are comparable to the rest of the sample and that the majority believe that tourism contributes to climate change $(M=3.17$, Standard Deviation $=0.983)$. However, they prioritise personal interests over concern for their contribution to climate change:

"I now find it important to travel to have a break from the wind, and so factor in travel as a priority, not a luxury"

There was also mention that some changes may be permanent, and as such it was important to visit destinations before it is too late, as reflected in these statements: 
"There is a sad urgency to get to some places before they disappear"

"It makes me want to see things before they are gone"

These statements show that some of the respondents do not wish to change their behaviours even if they think that they are harmful to the environment. Studies by Dawson, Stewart, Lemelin, and Scott (2010) and Farbotko (2010) have found that there is a growth in "last chance tourism", which can be argued to capitalise on the devastating effects that climate change, and by implication tourism, has on certain parts of the world. The paradox posed here is that the respondents have seen changes in the climate and have interpreted these as evidence of climate change; however, they do not care that their travel behaviour could be a contributing factor to the changes that they have observed.

Group 2 (eight respondents) reported travelling at other times of the year (season) or to other destinations, without evidence of the reported changes resulting in decreasing the respondents' negative impacts on the global natural environment.

"Travel needs to be timed with favourable weather"

"We worry about heatwaves, so [we are] now going at what were once cooler times of the year"

It has been predicted by several researchers that changes to seasonality may occur as a result of a changing climate at the origin or at the potential destinations (Amelung, Nicholls, \& Viner, 2007; Bigano, Hamilton, \& Tol, 2007). The above statements indicate that these projections are already being observed and beginning to influence holiday decision-making.

Group 3 (eight respondents) reported that they have a "need" to go away on holiday but that decisions are moderated by a concern for the natural environment. The respondents in this group appear to be aware of the necessity to act and are willing to make compromises; however, they appear to be unwilling to change the frequency of travel as well as the distance to the destination:

"[I] try to travel on eco-conscious tour companies and take their advice re eco friendly behaviour. I have begun to use carbon offset programme/fly airlines [sic] who offer them." 
As pointed out by Becken (2007), the freedom to travel is ingrained in people's minds, and most would not give up that freedom, even if they are aware of its negative impact on the natural environment. Behaving in an environmentally responsible manner thus becomes a compromise, possibly a way of clearing a guilty conscience.

Members of Group 4 (seven respondents) commented that they travel less as a result of observations and concern about climate change. These respondents reported awareness of the link between tourism and climate change and chose to take responsibility for their contribution.

"We try not to fly/see family friends only for important occasions. Discuss whether appropriate to fly for events."

"Fly overseas less, try to use public transport."

This highlights that some respondents, albeit a very small group ( $2 \%$ of sample), reported that they make sacrifices in order to mitigate the negative effects of their behaviours on the global natural environment. Considering the measures currently in place to limit the negative impacts of tourism on the environment (virtually none which impose change), it is encouraging to see that voluntary initiatives and education have reached at least some respondents and have acted as agents of change.

\section{Effective mitigation measures}

There has been much debate about which mitigation measures are the most appropriate and effective to change current behaviour. As noted by many researchers, and is also evident from the results presented above, people do not want to give up the freedom to travel (Becken, 2007; Hares et al., 2010; Lorenzoni et al., 2007). However, in order to reduce the negative impact that tourism has on the environment, there has to be a change in behaviour towards less travel (Peeters, 2010; Schott et al., 2010). It is thus clear that current mitigation initiatives are not adequate to deal with the increasing problem that GHG emissions from tourism present.

To identify preferred demand-focused mitigation strategies in light of the increasingly tangible nature of climate change, the respondents were asked to select the preferred strategy from the list given in Figure 2. The distribution of responses illustrates that the most popular option was "educational campaigns" (52\%) to inform people about the negative impacts that travelling can have on the environment. This type of measure leaves people the option of maintaining their current behaviour, as emphasised by this study, and will as such not provide a rapid solution to the problem of limiting GHG emissions from tourism. The second most popular measure was to 
introduce legislation in the form of a carbon tax (24\%), but for this tax to be collected from transport companies and not from consumers. "Voluntary offsetting schemes for consumers" was the third most popular choice, and $4 \%$ of the respondents selected "none". The data (Figure 2) then display a clear trend of the respondents either suggesting that consumers should be influenced through soft measures such as education or voluntary opportunities for offsetting or shifting the responsibility for climate change mitigation to tourism businesses. This serves as a clear message that the respondents wish to be able to maintain their current behaviours despite a relatively high awareness and reported evidence of tangible climate change impacts occurring already.

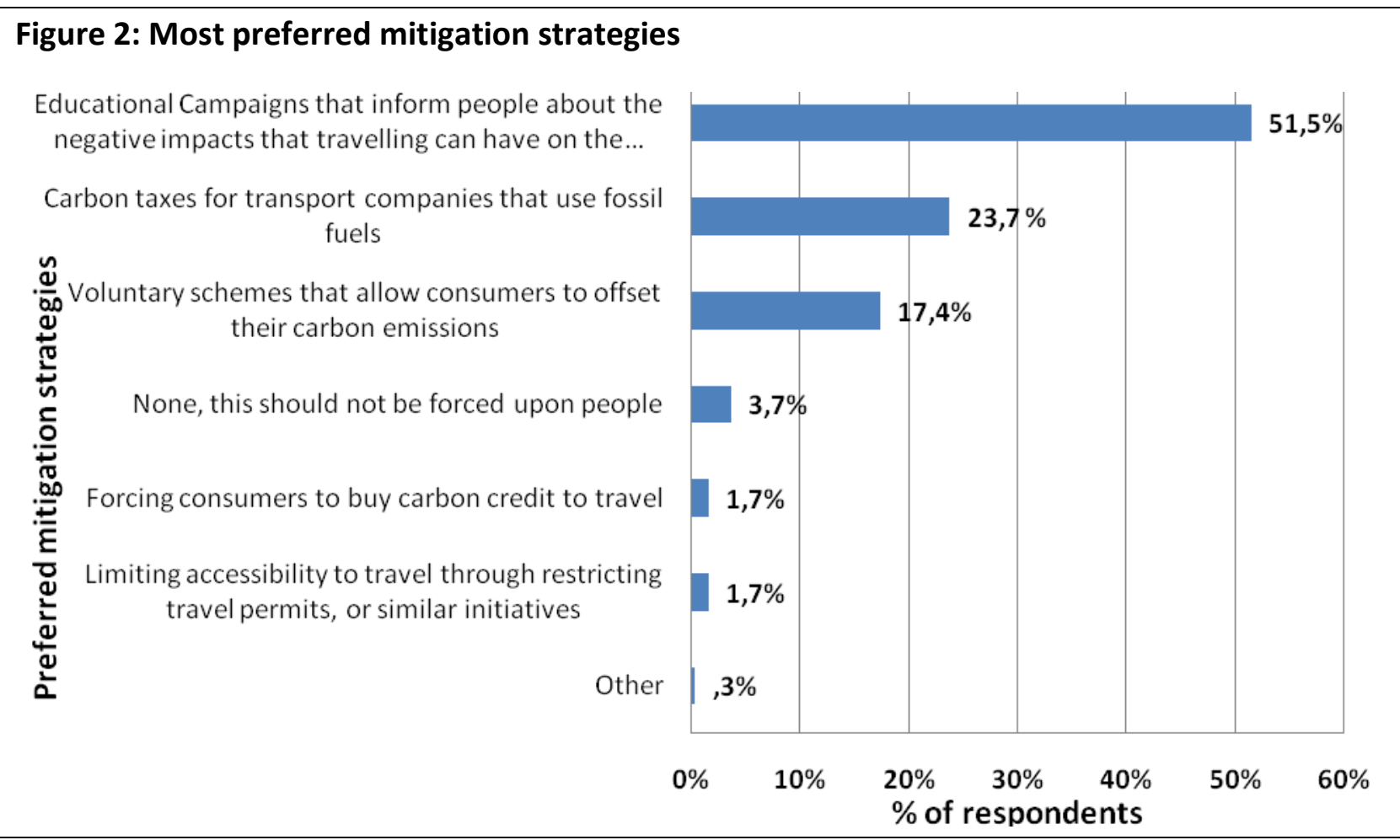

The question who should take the main responsibility for mitigating tourism's negative impacts on the natural environment was posed to identify whether there was a willingness to change tourism consumption behaviour. The five options that were available were United Nations, national governments, providers of tourism products, consumers (tourists), or other. The majority of the respondents (45\%) felt that the main responsibility should lie with the national government, followed by $22 \%$ suggesting providers of tourism products. It is again worth noting that only $17 \%$ of the respondents think that the main responsibility should lie with the individual. This is in line with previous studies in which it was noted that respondents want governments to take the lead in dealing with this issue (Lorenzoni et al., 2007; Whitmarsh, 2009). 


\section{Conclusion}

While the respondents in this study had a high awareness of climate change and its causes, this rarely affected their recent holiday decision-making. As in other recent studies on this topic (Barr et al., 2010; Becken, 2007; Hares et al., 2010), the commonly referred to "attitudebehaviour gap" is also documented in this study, although it is better described as an "awareness-action gap" in this context. The lack of action in this study is complemented by a rejection of personal responsibility; the respondents prefer mitigation strategies which place the responsibility with an external agent such as the national government or tourism providers.

The first aim of this study was to explore the respondents' awareness of climate change and concern about its effects on their lives. People in the sample seemed to be aware of the contribution of tourism to climate change, as the largest proportion (56\%) agreed that tourism within New Zealand contributes to global climate change. Additionally, $67 \%$ of the respondents in this study thought that it was likely that climate change would have a negative impact on their daily lives in New Zealand within the next 20 years. It is thus clear that people are aware of the potential changes that may occur, and they believe that changes will happen at a relatively rapid pace.

The second aim was to examine the respondents' recent holiday decision-making to identify whether and how this awareness and/or concern impacts on their tourism-related decisions and behaviour. A surprisingly high percentage of the respondents (43\%) reported that they had already observed evidence of climate change in their home environment. Interestingly, in most cases, the observations did not prompt the respondents to change their behaviours. When analysing the reported changes, noteworthy and disparate patterns of behavioural change were discovered. While most people changed their behaviours to act in a way that to some extent lessened their negative impact on the environment, others opted to increase their frequency of travel as a result of having observed climate change - even if the respondents believed tourism to be a contributing force to climate change. The reasons given for this change in behaviours included adverse change in climate at home and wanting to "see things before it is too late". The latter point presents a paradox, namely the travellers going to see a destination before it becomes "destroyed" by climate change are in effect contributing to its demise. Similar findings emerged in other recently published studies by Dawson et al. (2010) and Farbotko (2010).

What is perhaps most alarming is that the proportion of people who reported changing their behaviour for the "worse" after observing what they interpreted as evidence of climate change is roughly the same as that of people who have changed their behaviour for the "better", 
although both groups are very small. Generally, while the connection between tourism and climate change is made by the majority, few attempts are made to mitigate climate change on the personal level. This reinforces the notion that current mitigation strategies which rely on individual action are not effective in reducing the negative impact of tourism from and within New Zealand on the environment.

The third aim was to identify preferences for demand-focused strategies aimed at reducing the GHG emissions generated by tourism. Research done in Britain established that people were not adopting voluntary government strategies created to mitigate climate change (Whitmarsh, 2009). This may also be the case in New Zealand should the government rely on voluntary initiatives to induce change, given that the respondents in the most part do not make use of the opportunities that currently exist. It is also clear that the respondents on the whole wanted to deflect any mitigation obligations on to other stakeholders as they preferred soft measures such as education and indicated that the primary mitigation role should lie with national governments. If the global temperature rise is to be kept at a maximum of $28 \mathrm{C}$, as is recommended by the IPCC (2007), then an immediate response is needed. This means that forcing people to change by means of legislation is likely to be the most effective mechanism to achieve behavioural change in the short term, as voluntary action is repeatedly found to be adopted only by a comparatively small number of people. An example of a piece of legislation which is expected to lead to tangible long-term impacts on travel behaviour is the UK's increased departure tax, commonly referred to as a "green tax" (Pearce \& Schott, 2010); the tax requires an additional charge of NZ\$144 for one person to fly economy class from the UK to New Zealand, compared to the pre 2007 Air Passenger Duty. However, this does not mean that valuable psychological insights into the barriers to voluntary action (Schott et al., 2010) should be dismissed, but rather more research on these barriers and how to overcome them is required.

An important step in creating wider acceptance and support for policies and specific legislation capable of triggering relatively rapid changes to current travel behaviours is effective and targeted education about climate change and its implications. The findings of this study suggest that certain groups in society should be specifically targeted when creating educational campaigns as knowledge about the relationship between tourism and climate change reaches those in society with higher levels of education, but not those who stop their education after high school. Similarly, younger people were found to have more knowledge about this relationship than older generations. As such, educational campaigns aimed at raising awareness about climate change and a person's contributions in order to support broader government-led policies should target groups in society with lower exposure to post-school education as well as older generations. Sourbati (2009) noted that older people use the internet less often than 
young people. As such, using TV, radio, and print media as the means of educating those who do not actively seek out information about climate change is likely to succeed in reaching not only older people but also those with less exposure to post-school education. However, ultimately more research is needed to identify an appropriate mix of education and legislation that has the capacity to activate a meaningful behavioural change in the context of tourism.

\section{References:}

Amelung, B., Nicholls, S., \& Viner, D. (2007). Implications of global climate change for tourism flows and seasonality. Journal of Travel Research, 45, 285-296.

Barr, S., Shaw, G., Coles, T., \& Prillwitz, J. (2010). A holiday is a holiday: Practicing sustainability, home and away. Journal of Transport Geography, 18(3), 474-481.

Becken, S. (2007). Tourists' perception of international air travel's impact on the global climate and potential climate change policies. Journal of Sustainable Tourism, 15(4), 351-368.

Bigano, A., Hamilton, J.M., \& Tol, R.S.J. (2007). The impact of climate on holiday destination choice. Climatic Change, 76, 389-406.

Burns, P., \& Bibbings, L. (2009). The end of tourism? Climate change and societal challenges. Twenty First Centuries, 4(1), 31-51.

Chug, K. (2011, April 1). Scientists give chilling warning on climate. The Dominion Post. Retrieved from http:// www.stuff.co.nz/dominion-post/news/4834568/ Scientists-give-chillingwarnings-on-climate.

Dawson,J., Stewart, E.J., Lemelin, H., \& Scott, D. (2010). The carbon cost of polar bear viewing tourism in Churchill, Canada. Journal of Sustainable Tourism, 18(3), 319-336.

Dolcinar, S., \& Leisch, F. (2008). An investigation of tourists' patterns of obligation to protect the environment. Journal of Travel Research, 46, 381-391.

Fairweather, J.R., Maslin, C., \& Simmons, D.G. (2005). Environmental values and response to ecolabels among international visitors to New Zealand. Journal of Sustainable Tourism, 13(1), 82-98. 
Farbotko, C. (2010). The global warming clock is ticking so see these places while you can: Voyeuristic tourism and model environmental citizens on Tuvalu's disappearing islands. Singapore Journal of Tropical Geography, 31, 224-238.

Gössling, S. (2002). Global environmental consequences of tourism. Global Environmental Change, 12, 283-302.

Gössling, S., Bredberg, M., Randow, A., \& Sandström, E. (2006). Tourist perceptions of climate change: A study of international tourists in Zanzibar. Current Issues in Tourism, 9(4\&5), 419435.

Gössling, S., Haglund, L., Kallgren, H., Revahl, M., \& Hultman, J. (2009).Swedish air travellers and voluntary carbon offsets: Towards the co-creation of environmental value? Current Issues in Tourism, 12(1), 1-19.

Graburn, N.H.H. (1983). The anthropology of tourism. Annals of Tourism Research, 10(1), 9-33.

Hares, A., Dickinson, J., \& Wilkes, K. (2010). Climate change and the air travel decisions of UK tourists. Journal of Transport Geography, 18(3), 466-473.

IPCC. (2007). IPCC fourth assessment report: Climate change 2007 (AR4). Retrieved February 25, 2009, from http://www.ipcc.ch/

Jagers, S.C. (2009). In search of the ecological citizen. Environmental Politics, 18(1), 18-36.

Lopez, A.G., \& Cuervo-Arango, M.A. (2008). Relationship among values, beliefs, norms and ecological behaviour. Psicothema, 20(4), 623-629.

Lorenzoni, I., Nicholson-Cole, S., \& Whitmarsch, L. (2007). Barriers perceived to engaging with climate change among the UK public and their policy implications. Global Environmental Change, 17, 445-459.

Lorenzoni, I., \& Pidgeon, N.F. (2006). Public views on climate change: European and USA perspectives. Climatic Change, 77, 73-95.

Lübbert, C. (2001). Tourism ecolabels market research in Germany. In X. Font \& R. Buckley (Eds.), Tourism ecolabelling: Certification and promotion of sustainable management (pp. 7186). Oxon: CABI Publishing. 
Milfont, T. (2010). Global warming, climate change and human psychology. In V. CorralVerdugo, C. Garcia-Cadena \& M. Frias-Armenta (Eds.), Psychological approaches to sustainability: Current trends in theory, research and practice (pp. 19-42). New York, NY: Nova Science.

NIWA. (2009). Climate. Retrieved April 20, 2009, from http://www.niwa.co.nz/ourscience/climate/ information-and-resources/clivar/scenarios.

Norgaard, K.M. (2006). We don't really want to know: Environmental justice and socially organized denial of global warming in Norway. Organization Environment, 19(3), 347-370.

NZBCSD. (2009). New Zealand climate change survey. Retrieved March 23, 2009, from http://www.nzbcsd.org.nz/_attachments/New_Zealanders\%27Attitudes_to_Climate_Change_S hapeNZ_Survey_Report_March\%2C_2009.pdf

Pawlik, K. (1991). The psychology of global environmental change: Some basic data and an Agenda for cooperative international research. International Journal of Psychology, 26, 547563.

Pearce, D.G. \& Schott, C. (2010). Tourism and climate change: Public and private sector responses in New Zealand. In C. Schott (Ed.), Tourism and the implications of climate change: Issues and actions (pp. 50-63). Bingley: Emerald Publishers.

Peeters, P. (2010). Tourism transport, technology and carbon dioxide emissions. In C. Schott (Ed.), Tourism and the implications of climate change: Issues and actions (pp. 67-90). Bingley: Emerald Publishers.

Reiser, A., \& Simmons, D.G. (2005). A Quasi-experimental method for testing the effectiveness of ecolabel promotion. Journal of Sustainable Tourism, 13(6), 590-616.

Schott, C. (2006). Proactive crises management tools: Ecolabel and green globe 21 experiences from New Zealand. Tourism Review International, 10, 81-90.

Schott, C., Reisinger, A., \& Milfont, T.L. (2010). Tourism and climate change: Interrelationships and implications. In C. Schott (Ed.), Tourism and the implications of climate change: Issues and actions (pp. 1-24). Bingley: Emerald Publishers. 
Sourbati, M. (2009). It could be useful, but not for me at the moment': Older people, internet access and e-public service provision. New Media and Society, 11(7), 1083-1100.

Statistics New Zealand (2011). 2006 Census data. Retrieved April 2, 2011, from http://www.stats.govt. nz/Census/2006CensusHomePage.aspx

Stoll-Kleemann, S., O'Riordan, T., \& Jaeger, C.C. (2001). The psychology of denial concerning climate mitigation measures: Evidence from Swiss focus groups. Global Environmental Change, 11, 107-117.

UNWTO (United Nations World Tourism Organisation). (2009). Index. Retrieved November 5, 2009, from http://www.unwto.org/index.php

UNWTO-UNEP-WMO (United Nations World Tourism Organization, United Nations Environment Program and World Meteorological Organization) (2008). Climate change and tourism: Responding to global challenges. Madrid: United Nations World Tourism Organization.

Whitmarsh, L. (2009). Behavioural responses to climate change: Asymmetry of intentions and impacts. Journal of Environmental Psychology, 29, 13-23.

World Bank. (2010).Public attitudes toward climate change: Findings from a multi-country poll. Retrieved August 2010, from http://siteresources.worldbank.org/INTWDR 2010/Resources/CC_Poll_Report_July_01_2010.pdf 